\title{
Job stress, fatigue, and job dissatisfaction in Dutch lorry drivers: towards an occupation specific model of job demands and control
}

\author{
E M de Croon, R W B Blonk, B C H de Zwart, M H W Frings-Dresen, J P J Broersen
}

See end of article for authors' affiliations

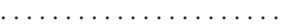

Correspondence to: Drs E M de Croon, Coronel Institute for Occupational and Environmental Health, Academic Medical Center / University of Amsterdam, Meibergdreef 15, 1105

AZ Amsterdam, The

Netherlands;

e.m.decroon@amc.uva.nl

Accepted

17 October 2001

\begin{abstract}
Objectives: Building on Karasek's model of job demands and control (JD-C model), this study examined the effects of job control, quantitative workload, and two occupation specific job demands (physical demands and supervisor demands) on fatigue and job dissatisfaction in Dutch lorry drivers.

Methods: From 1181 lorry drivers (adjusted response 63\%) self reported information was gathered by questionnaire on the independent variables (job control, quantitative workload, physical demands, and supervisor demands) and the dependent variables (fatigue and job dissatisfaction). Stepwise multiple regression analyses were performed to examine the main effects of job demands and job control and the interaction effect between job control and job demands on fatigue and job dissatisfaction.

Results: The inclusion of physical and supervisor demands in the JD-C model explained a significant amount of variance in fatigue (3\%) and job dissatisfaction (7\%) over and above job control and quantitative workload. Moreover, in accordance with Karasek's interaction hypothesis, job control buffered the positive relation between quantitative workload and job dissatisfaction.

Conclusions: Despite methodological limitations, the results suggest that the inclusion of (occupation) specific job control and job demand measures is a fruifful elaboration of the JD-C model. The occupation specific JD-C model gives occupational stress researchers better insight into the relation between the psychosocial work environment and wellbeing. Moreover, the occupation specific JD-C model may give practitioners more concrete and useful information about risk factors in the psychosocial work environment. Therefore, this model may provide points of departure for effective stress reducing interventions at work.
\end{abstract}

n many sectors of industry, the nature of work has changed considerably over the past decades. ${ }^{12}$ Important changes concern making work more flexibile, the entry of the 24 hour economy, mechanisation, automation, and the appliance of information and communication technology. In general, these changes have resulted in a decreased exposure to physical and chemical agents and an increased exposure to psychosocial risk factors. In the road transport industry, for instance, the entry of the 24 hour economy has been accompanied by an increased demand for just in time deliveries leading to an intensification of the work of lorry drivers. ${ }^{3}$ Furthermore, the appliance of communication technology has led to a decreased feeling of independence and tighter time schedules for these workers. ${ }^{4}$

These changes in the nature of work have gone hand in hand with an increased attention in occupational health research directed at the investigation of the relation between psychosocial work factors and health and wellbeing. Several occupational stress models have been postulated that can serve as a theoretical frame for this category of studies. Without doubt, the most influential and successful is the model of job demands and control (JD-C model) described by Karasek and Theorell. ${ }^{5}$

Initially, the JD-C model was based on the hypothesis that psychological demands result in psychological strain and physical illness only when the level of decision latitude, later referred to as job control, is low. ${ }^{5}$ Stated differently, Karasek assumed that decision latitude buffers the harmful effect of high demand jobs (stress buffering hypothesis of job control). Because most studies that examined the JD-C model favour an additive rather than an interactive effect of psychological demands and decision latitude on health and wellbeing, Karasek revised the initial core hypothesis. ${ }^{7}$ Presently, the
JD-C model posits that the most adverse reactions of psychological strain occur when the psychological demands are high and job control is low. ${ }^{6}$ This proposition is generally labelled the psychological strain hypothesis. Furthermore, Karasek and Theorell added a social support dimension to the JD-C model. ${ }^{6}$ The extended model of job demands, control, and support (JD-CS model) states that working situations which are characterised by high demands, low control, and low social support have the most negative effects on employee health and wellbeing.

The JD-C(S) model has often been disputed. ${ }^{8-12}$ One important topic of debate concerns the conceptualisation of decision latitude. According to Karasek, ${ }^{5}$ decision latitude (job control) consists of two subconcepts: decision authority and skill discretion. Decision authority is defined as the social authority over making decisions. ${ }^{6}$ Skill discretion refers to the breadth of skills usable on the job. ${ }^{6}$ Whereas decision authority is conceptually equivalent to job control, skill discretion represents a different concept. Consequently, there has been a lack of agreement between the way job control is generally conceived and used in the field of occupational stress research and the way this work feature has been conceived and used in most JD-C(S) studies.

Over the past years, more studies have met this criticism. These particular studies ${ }^{13-17}$ have attempted to improve Karasek's control construct by omitting items of the skill discretion subconcept and simultaneously enclosing items

Abbreviations: JD-C model, model of job demands and control; JD-CS model, model of job demands, control, and support; VBBA, Dutch questionnaire on the experience and assessment of work 
focused clearly on the opportunities provided by the job to exert influence over the work setting.

A second objection raised to the JD-C(S) model involves the conceptualisation and measurement of job demands. According to Karasek and Theorell work load, measured at a general level with subjective items such as "work hard" and "excessive work", is the central component of this dimension. ${ }^{6}$ However, other job demands may be important predictors of health and wellbeing for certain occupations as well. ${ }^{18}$ Lorry driving is an exemplary occupation in this respect. As well as a high quantitative workload, the work of lorry drivers is characterised by high physical demands-for example, prolonged sitting in a single body posture, loading and unloading of the goods ${ }^{19}{ }^{20}$ and unfavorable working hours. ${ }^{19}$ Also, lorry driving is mentally demanding because it requires long periods of alertness and sustained attention. Finally, lorry drivers often complain of an authoritative and punitive attitude from front line supervisors ${ }^{321} 22$ which suggests that not only the absence of positive relations (social support), but also the presence of negative relations (conflicts) may effect the health and wellbeing of these workers.

The conceptual criticisms of the JD-C(S) model already described bring about two restrictions. The first restriction relates to the stress buffering hypothesis of job control. ${ }^{5}$ The chance of identifying interaction effects between job demands and job control, both measured at a general level, is small. The importance of using distinctive, instead of generic, measures of job control and job demands when examining the stress buffering hypothesis of job control was shown by Sargent and Terry $^{23}$ and Van der Doef and Maes. ${ }^{24}$ These researchers showed that some aspects of job control-for example, control over work pace and work method-may protect workers from the harmful effects of certain types of job demands-for example, time pressure-whereas others do not. Stated differently, depending on the particular domain of job control under consideration, different job demands may be differentially related to health and wellbeing. Although the importance of using specific and distinctive measures for this is not an unknown topic in the stress literature, ${ }^{25}$ most research workers examining the JD-C(S) model have overlooked this topic.

The related issue of practical applicability is the second restriction that accompanies the conceptual comments on the JD-C(S) model. Several investigators argue that research findings based on the JD-C(S) model give a rather abstract picture of the relation between the psychosocial work environment and wellbeing. ${ }^{118}{ }^{18}$ For this reason, several researchers have recommended incorporating a range of more concrete demanding work features in the JD-C(S) model. ${ }^{11}{ }^{14}$ This may explain more variance in outcomes of wellbeing of employees and is likely to provide practical points of departure for interventions. In view of the changing nature of work and the increased call upon evidence based practice in occupational health care, concrete information about risk factors in the psychosocial work environment, based on specific occupational stress models, is badly needed. ${ }^{11}$

The restrictions already described that accompany the application of the JD-C(S) model in occupational stress research and practice formed the incentive for this study. The aim of the present study was to evaluate a modified JD-C model in which one focused measure of job control (control over work method and work pace) and quantitative workload, as well as two job demands which are specific for lorry driving (physical demands and supervisor demands) were included. In accordance with the psychological strain hypothesis, ${ }^{6}$ it was expected that job control and quantitative workload would have additive effects on wellbeing in lorry drivers. Furthermore, it was expected that the inclusion of physical and supervisor demands would improve the predictive power of the additive JD-C model. Finally, in view of the distinctiveness and greater specificity of these measures, interactive effects were expected to be detected between job control and job demands on wellbeing in lorry drivers.

\begin{tabular}{|c|c|c|c|}
\hline Variable & Mean & SD & Range \\
\hline $\begin{array}{l}\text { Age (y) } \\
\text { Male \% }\end{array}$ & $\begin{array}{l}39.1 \\
98.1\end{array}$ & 10.1 & $19-68$ \\
\hline Working hours/week & 57.4 & 11.7 & $7-90$ \\
\hline
\end{tabular}

\section{METHODS}

Subjects

In August 1998, self completed questionnaires were sent to the home addresses of a random sample $(n=2000)$ of the population of lorry drivers in the Dutch road transport industry. Initially, a total of 1277 questionnaires were returned. Of these, 52 were not completed because the address was wrong resulting in an adjusted response rate of 63\% (1225/1948). All lorry drivers with missing values on the key study variables were excluded from the analyses, which reduced the number of participants to 1181. Table 1 shows information on age, sex, and number of working hours of the study sample. Most of the participants (98\%) were men. Mean (SD, range) age of the participants was 39 (10.1, 19-68) years. Participants worked a mean (SD, range) of 57 (11.7, 7-90) hours/week.

\section{Questionnaire}

All independent variables (job control, quantitative workload, physical demands, and supervisor demands) were measured with the validated Dutch questionnaire on the experience and assessment of work (VBBA). ${ }^{26}$ This questionnaire has been widely used in The Netherlands in both research on occupational stress $\mathrm{s}^{27-32}$ and in daily practice as a tool for occupational health services. ${ }^{33}$ The psychometric qualities of the VBBA scales are good. ${ }^{34}$ During construction of the scales $\rho$ varied between 0.82 tot 0.95 , and the Loevinger's $H$ varied between 0.42 and 0.75 . An external test of the psychometric properties indicated somewhat less favorable, but still convincing psychometric properties. ${ }^{35}$

\section{Job control}

Job control was measured with an 11 item scale, including items from the focused measure of timing control and method control developed by Jackson et al. ${ }^{36}$ Some examples of this scale are: "Can you decide on your own the order in which you carry out your work?" and "Can you interrupt your work for a short time if you find it necessary to do so?". Items were scored on a four point scale $(\mathrm{l}=$ never, $2=$ sometimes, $3=$ often, $4=$ always).

\section{Job demands}

\section{Quantitative workload}

Quantitative workload was assessed by an 11 item scale. Two example items are: "Do you work under pressure of time?" and "Do you have to work extra hard to complete something?".

\section{Physical demands}

Physical demands were assessed by a seven item scale. Typical items of this scale are: "Does your work require physical strength?" and "In your work, are you seriously inconvenienced by having to lift or move loads?".

\section{Supervisor demands}

Supervisor demands were measured by the relation with your immediate boss scale of the VBBA comprising nine items. Some examples of this scale are: "Do you have conflicts with your boss?" and "Do you experience aggressiveness from your boss?". All items were scored on a four point scale ( $1=$ never, $2=$ sometimes, $3=$ often, $4=$ always ). 
Table 2 Range, mean (SD), internal consistency $(\alpha)$, and zero order Pearson correlations of the study variables $(n=1181)$

\begin{tabular}{|c|c|c|c|c|c|c|c|c|c|c|}
\hline Variable & Range & Mean & SD & $\alpha$ & 1 & 2 & 3 & 4 & 5 & 6 \\
\hline Age & $19-68$ & 39.09 & 10.13 & - & - & - & - & - & - & - \\
\hline Job control & $0-100$ & 53.47 & 21.22 & 0.90 & 0.03 & - & - & - & - & - \\
\hline Quantitative workload & $6-97$ & 44.89 & 16.40 & 0.88 & 0.08 & $-0.43^{*}$ & - & - & - & - \\
\hline Physical demands & $0-100$ & 34.94 & 21.09 & 0.88 & 0.00 & $-0.15^{*}$ & $0.47^{*}$ & - & - & - \\
\hline Supervisor demands & $0-100$ & 27.68 & 20.21 & 0.89 & 0.02 & $-0.40^{*}$ & $0.46^{*}$ & $0.37^{*}$ & - & - \\
\hline Fatigue & $20-137$ & 50.09 & 23.12 & 0.90 & 0.06 & $-0.33^{*}$ & $0.44^{*}$ & $0.29 *$ & $0.38 *$ & - \\
\hline Job dissatisfaction & $0-100$ & 15.97 & 24.79 & 0.87 & -0.01 & $-0.32 *$ & $0.50 *$ & $0.38 *$ & $0.45^{*}$ & 0.49 * \\
\hline
\end{tabular}

\section{Dependent variables}

\section{Fatigue}

Fatigue was measured with the checklist individual strength (CIS).$^{37}$ The CIS consists of 20 statements for which the person has to indicate on a seven point scale to what extent the particular statement applies to him or her. The statements refer to four aspects of fatigue experienced during the previous 2 weeks, namely subjective fatigue (eight items-for example, "I feel tired"), reduction in motivation (four items-for example, "I feel no desire to do anything"), reduction in activity (three items-for example, "I don't do much during the day"), and reduction in concentration (five items-for example, "My thoughts easily wander"). The CIS is well validated in the clinical setting. ${ }^{38}$ Recently, the validity of the questionnaire was established also among working people. ${ }^{27}{ }^{39}$ In this study a composite CIS total score (ranging from 20 to 140) was calculated by adding the person's scores for the four factors.

\section{Job dissatisfaction}

Job dissatisfaction was assessed by the similarly named scale of the VBBA comprising nine dichotomous items. Some examples of the job dissatisfaction scale are: "I have to continually overcome my resistance to do my work" and "I find the thought that I shall have to do this job until I retire very oppressive".

\section{Data analysis}

To test the stated hypotheses, stepwise multiple regression analyses were conducted on both fatigue and job dissatisfaction. In the first step job control and Karasek's central job demands component, quantitative workload, were entered into the equation. The two occupation specific demands (physical demands, and supervisor demands) were entered into the equation in the second step. To test the hypothesised interaction between job control and job demands, three interaction terms (job control×quantitative workload, job control×physical demands, and job control×supervisor demands), computed as the product of the standard scores of the independent variables, ${ }^{40}$ were entered into the equation in the final step three. In all the analyses effects were accepted as significant at $\mathrm{p}<0.01$.

\section{RESULTS}

\section{Preliminary analyses}

Table 2 presents range, mean, SD, internal consistency (Cronbach's $\alpha$ ), and zero order Pearson correlations of all study variables. Inspection of table 2 shows that, with the exception of age, all the correlations between the study variables were significant $(\mathrm{p}<0.01)$. Because the correlation analyses did not show any significant correlation between age and the other variables, there was no need to control for age in further analyses.

The results of the multiple regression analyses examining the main and interaction effects of job demands and job control on fatigue and job dissatisfaction are shown in table 3 . The results of the analyses for fatigue indicated that the proportion of variance accounted for in fatigue increased from 0.00 to 0.22 with the addition of job control and quantitative workload (step one). The entry of physical demands and supervisor demands in step two accounted for another 3\% of variance in fatigue. Introduction of the interaction terms in step three did not result in a further increase in $R^{2}$. At the final step three, job control $(\beta=-0.14)$, quantitative workload $(\beta=0.26)$, physical demands $(\beta=0.09)$ and supervisor demands $(\beta=0.16)$ were uniquely related to fatigue.

The stepwise multiple regression analyses of job dissatisfaction showed a significant increase in $R^{2}$ from 0.00 to 0.26 when job control and quantitative workload were entered into the equation (step one). The entry of physical and supervisor demands in step two accounted for $7 \%$ of additional variance in job dissatisfaction. Introduction of the interaction terms in step three resulted in a further increment of $R^{2}$ from 0.33 to

Table 3 Stepwise multiple regression analyses of job control and job demands and the interaction between job control and job demands on fatigue and job dissatisfaction $(n=1181)$

\begin{tabular}{|c|c|c|c|c|}
\hline \multirow[b]{2}{*}{ Predictor } & \multicolumn{2}{|l|}{ Fatigue } & \multicolumn{2}{|c|}{ Job dissatisfaction } \\
\hline & $\beta$ & $R^{2}$ change & $\beta$ & $\mathrm{R}^{2}$ change \\
\hline \multicolumn{5}{|l|}{ Step 1: } \\
\hline Job control & $-0.14^{*}$ & $0.22^{*}$ & -0.10 * & $0.26 *$ \\
\hline Quantitative workload & $0.26^{*}$ & & $0.27^{*}$ & \\
\hline \multicolumn{5}{|l|}{ Step 2: } \\
\hline Physical demands & $0.09 *$ & $0.03 *$ & $0.15^{*}$ & $0.07^{*}$ \\
\hline Supervisor demands & $0.16^{*}$ & & $0.20^{*}$ & \\
\hline \multicolumn{5}{|l|}{ Step 3: } \\
\hline Controlxquantitative workload & -0.04 & 0.00 & $-0.14^{*}$ & $0.04 *$ \\
\hline Controlxphysical demands & -0.02 & & -0.04 & \\
\hline Controlxsupervisor demands & -0.01 & & -0.06 & \\
\hline
\end{tabular}




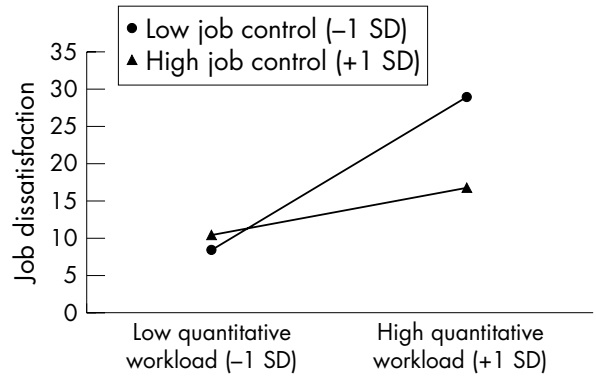

Figure 1 Interaction between quantitative workload and job control on job dissatisfaction.

0.37. Job control $(\beta=-0.10)$, quantitative workload $(\beta=0.27)$, physical demands $(\beta=0.15)$, supervisor demands $(\beta=0.21)$, and the interaction between job control and quantitative workload $(\beta=0.14)$ were found to contribute significantly and uniquely to the variance in job dissatisfaction.

In figure 1 the interaction between quantitative workload and job control on job dissatisfaction is graphically represented by the method recommended by Jaccard et al. ${ }^{41}$ As shown in figure 1 , quantitative workload is strongly related to job dissatisfaction at low levels of job control, whereas a weak relation between quantitative workload and job dissatisfaction is found at high levels of job control.

\section{DISCUSSION}

The aim of the present study was to evaluate a modified JD-C model in which a focused measure of job control (control over work method and work pace) and two occupation specific job demands were included. The study brought about two important findings. Firstly, the inclusion of physical and supervisor demands into the JD-C model improved the predictive power of the additive model. Secondly, in accordance with Karasek's interaction hypothesis, job control buffered the impact of quantitative workload on job dissatisfaction.

In accordance with our expectation the inclusion of physical and supervisor job demands improved the predictive power of the additive JD-C model. For fatigue a moderate amount of variance was accounted for by the two occupation specific job demands over and above that accounted for by quantitative workload and job control. A more substantial improvement of the model's predictive power was found when job dissatisfaction was regressed on the independent variables.

These findings confirm other studies that show that a range of work features which are specific for a particular occupation should be considered for a full comprehension of the relation between the psychosocial work environment and health and wellbeing. ${ }^{18}{ }^{14} 42$ Although Karasek and Theorell themselves ${ }^{6}$ have suggested that more work dimensions are required to capture the psychosocial work environment adequately, many researchers and practitioners still focus on only one global measure of job demands and job control. As a consequence, other demanding work features that may influence health and wellbeing in certain occupations are often overlooked in occupational stress research and practice.

Another aim of this study was to investigate the stress buffering hypothesis of job control. In view of the available evidence, ${ }^{23} 24$ it was proposed that the employment of precisely defined, instead of globally defined, job demand and job control concepts would result in support for this hypothesis. The interaction effects between quantitative workload and job control on job dissatisfaction confirmed the stress buffering hypothesis. However, the failure to find any interaction between job control and the other job demands disproved the buffering hypothesis.

According to the stress matching hypothesis of Cohen and Wills ${ }^{25}$ there must be a reasonable match between the coping

\section{Main findings}

- The inclusion of job demands which are specific for lorry driving improved the predictive power of the model of job demands and control for fatigue and job dissatisfaction in this occupation.

- Job control buffered the detrimental effect of quantitative workload only, suggesting that the extent to which job demands impact on wellbeing depends on the match between the type of job control and job demand under consideration.

\section{Policy implications}

- Improving psychosocial work conditions of lorry drivers may strengthen wellbeing of these workers.

- However, strategies of effective work stress interventions in the road transport industry should differ according to the wellbeing outcome on target.

- In general, researchers and practitioners should use occupational stress models and instruments including a range of job demands which are useful in describing the psychosocial work environment which is specific to a particular occupation.

requirements of a certain stressor or demand and the available coping resources for buffering to occur. Interpretation of the present results in the light of that hypothesis, then leads to the suggestion that control over work method and work pace provides an effective resource for workers to cope with a high quantitative workload only. More specifically, as set forth by Sargent and Terry, ${ }^{23}$ a worker who has too much work to do will handle the stress better if the job has some flexibility in allocation of time and energy to tasks. ${ }^{43}$ For instance, a lorry driver who can decide for himself or herself at what time and in what order to accomplish his route can adjust his work situation to his psychological needs and preferences and reduce stress. By contrast, a lorry driver in conflict with his front line supervisor might benefit more from the support of a coworker. ${ }^{44}$

This implies that confirmation of Karasek's interactive JD-C model is not only dependent on the inclusion of more specific variables, but depends also on the extent to which the specific coping resource matches the specific type of job demand. Stated differently, depending on the specific demands posed by a particular occupation, certain aspects of control or other coping resources may bring about a stress buffering effect whereas others may not. The inclusion of job demand and job control measures in the JD-C model, which are specific to a certain occupation, is therefore likely to result in a further improvement of the predictive power of the model. Moreover, from a practical point of view, such an approach will give practitioners more concrete and therefore more useful information upon which to base effective interventions. ${ }^{18} 1145$

Interestingly, job control buffered the positive effects of quantitative workload on job dissatisfaction whereas no buffering effect of job control was detected when fatigue was on target. A review of the literature shows that this finding does not constitute a solitary case. Many studies that examined the stress buffering effect of job control on job (dis)satisfaction, ${ }^{14} 152346-53$ also confirmed the hypothesis. By contrast, those studies that examined the stress buffering effect of job control on fatigue, ${ }^{54}$ or on equivalent conceptssuch as need for recovery, ${ }^{55}$ burnout, ${ }^{5657}$ and emotional exhaustion $^{14}{ }^{58}$-failed to confirm the hypothesis. The differential interaction effect between demands and control on the outcome measures runs counter to the implicit assumption of the JD-C model that the effects of job demands and job control on health and wellbeing are non-specific, ${ }^{6}$ In fact, they 
confirm Warr's proposal ${ }^{59}$ that different psychological outcomes may arise from a combination of separate sources.

The practical implication of the differential interaction effect found is that interventions aimed exclusively at increasing control over work pace and work method in jobs with high quantitative workload seem insufficient to prevent over fatigue in lorry drivers from advancing. Conversely, these types of interventions that increase control, may, in view of the present results, be quite effective when the promotion of job satisfaction in lorry drivers is intended.

Four aspects of the present study require some consideration. Firstly, it should be noted that the proposed modified JD-C model was not intended to incorporate all the variables required to explain the relation between the psychosocial work environment and wellbeing in lorry drivers. The modified model gives a more comprehensive picture of the psychosocial work environment of lorry drivers. However, other psychosocial work factors which were not considered in this study-for example, job insecurity, long and irregular working hours, contacts with fractious customers, and the work home interference-may influence health and wellbeing of these workers as well.

Secondly, the response rate in the present study was fairly high. Almost two thirds of the lorry drivers who were asked to participate in the study returned completed questionnaires. This high response may be due to the publicity given to the research project (distribution of bulletins) as well as the increased value employers and employees in the road transport industry in recent years have started to attach to occupational stress. ${ }^{21}$

Thirdly, in this study self completed questionnaires were used to assess both independent and dependent variables. As a consequence, unmeasured self report bias-for example, negative affectivity, mood, and social desirability-may have amplified the main effects of job demands and job control. Although Spector et $a l^{60}$ recently showed that the inflating effect of self report bias may be not so prominent, we attempted to minimise this potential influence by using descriptive measures of the independent variables. Furthermore, it should be noted that self report bias results in an underestimation rather than an overestimation of interaction effects. As set forth by Wall et $a l^{15}$ the influence of self report bias would be to inflate main effects of job demands and job control at the expense of the underlying interaction effects.

Fourthly, both independent and dependent variables were measured at one point of time. As a consequence of the cross sectional design, no firm basis was available for causal ordering. Stated differently, whether the occurrence of negative psychosocial work factors precede lowered psychological wellbeing or whether lowered psychological wellbeing precedes the occurrence of negative psychosocial work factors, or both, is not elucidated in this study.

Evidently, longitudinal research is needed to obtain a clearer picture of possible causal relations among job demands, job control, and health and wellbeing. More importantly, more intervention studies between job demands and control are required as only these studies can tell us whether changing demands or control promote health and wellbeing of the employee. As reported by Jones $e t$ al $l^{11}$ the few JD-C intervention studies contrast violently with the many studies of the effects of demands or control. The few JD-C intervention studies question the practical validity of this occupational stress model. In our opinion the practical as well as the theoretical validity of the JD-C model may be improved with the inclusion of a more precisely defined job control construct and job demand concepts which are useful in describing the psychosocial work environment which is specific to a particular occupation.

\section{Authors' affiliations}

E M de Croon, B C H de Zwart, M H W Frings-Dresen, J P J

Broersen, Coronel Institute for Occupational and Environmental Health,
Academic Medical Center, University of Amsterdam, Amsterdam, The Netherlands

R W B Blonk, TNO Work and employment, Hoofddorp, the Netherlands

J P J Broersen, SKB Center of expertise on health and work

\section{REFERENCES}

1 International Survey Research. Employee satisfaction: tracking European trends. London: ISR, 1995.

2 Paoli P. Second european survey on working conditions 1996. Dublin European Foundation for the Improvement of living and working conditions. Loaghlinstown: European Foundation, 1997. (No EF9726.)

3 Bos JJ, Klamer HK, Krijen G, et al. Werken in het wegvervoer over de weg. (Working in the road transport industry.) The Hague: COB/SER, 1984.

4 De Zwart BCH, Frings-Dresen MHW. Technologische ontwikkelingen en innovaties in het beroepsgoederenvervoer over de weg in relatie tot gezondheidsklachten. (Technological developments and innovations in the road transport industry in association with health complaints.) Amsterdam: Coronel Institute for Occupational and Environmental Health, Academic Medical Centre, University of Amsterdam, 2000.

5 Karasek RA. Job demands, job decision latitude, and mental strain: implications for job redesign. Administrative Science Quarterly 1979:24:285-309.

6 Karasek RA, Theorell T. Healthy work: stress, productivity and the reconstruction of working life. New York: Basic Books, 1990

7 Karasek RA. Control in the workplace and its health related aspects. In: Sauter SL, Hurrell JJ, Cooper CL, eds. Job control and worker health. Chichester: Wiley, 1989:129-60.

8 De Jonge J, Kompier MAJ. A critical examination of the demand-control-support model from a work psychological perspective. International Journal of Stress Management 1997;4:235-58.

9 Kristensen TS. Job stress and cardiovascular disease: a theoretical critical review. J Occup Health Psychol 1996;1:246-60.

10 Ganster DC. Worker control and well-being: a review of research in the workplace. Job control and worker health. In: Sauter SL, Hurell JJ, Cooper CL, eds. Job control and worker health. Chichester: Wiley, 1989:3-23.

11 Jones F, Bright JEH, Searle BJ, et al. Modeling occupational stress and health: the impact of the demand-control model on academic research and on workplace practice. Stress Med 1998;14:231-6.

12 Kristensen TS. The demand-control-support model: methodological challenges for future research. Stress Med 1995;11:17-26.

13 De Croon EM, Van der Beek AJ, Blonk RWB, et al. Job stress and psychosomatic health complaints among Dutch truck drivers: re-evaluation of Karasek's interactive demand-control model. Stress Med 2000;16:101-7.

14 De Jonge J, Mulder MGP, Nijhuis FJN. The incorporation of different demand concepts in the job demand-control model: effects on health care professionals. Soc Sci Med 1999;48: 1 149-60.

15 Wall TD, Jackson PR, Mullarkey S, et al. The demands-control model of job strain: a more specific test. Journal of Occupational and Organizational Psychology 1996;69:153-66.

16 De Jonge J, Dollard MF, Dormann C, et al. The demand-control model: specific demands, specific control, and well-defined groups. International Journal of Stress Management 2000;74:269-87

17 De Rijk AE, Le Blanc PM, Schaufeli WB. Active coping and need for control as moderators of the demand-control model: effects on burnout. Journal of Occupational and Organizational Psychology 1998;71:1-18.

18 Sparks K, Cooper CL. Occupational differences in the work-strain relationship: towards the use of situation-specific models. Journal of Occupational and Organizational Psychology 1999;72:219-29.

19 McDonald N. Fatigue, safety and the truck driver. London: Taylor and Francis, 1984.

20 Van der Beek AJ, Frings-Dresen MHW, Van Dijk FJH, et al. Loading and unloading by lorry drivers and musculoskeletal complaints. Int J Ind Ergonom 1994;12:13-23.

21 De Croon EM, Blonk RWB, Frings-Dresen MHW, et al. Stress in het beroepsgoederenvervoer. (Stress in the road transport industry.) Amsterdam: Coronel Instituut, Academisch Medisch Centrum / Universiteit van Amsterdam. Gouda (The Netherlands): BGZ Wegvervoer, 2000. (No 00-01.)

22 Orris $\mathbf{P}$, Hartman $D E$, Strauss $P$, et al. Stress among package truck drivers. Am J Ind Med 1997;31:202-10.

23 Sargent LD, Terry DJ. The effects of work control and job demands on employee adjustment and work performance. Journal of Occupational and Organizational Psychology 1998;71:219-36.

24 Van der Doef $M$, Maes S. The job demand-control-support model and psychological well-being: a review of 20 years of empirical research. Work Stress 1999;13:87-114.

25 Cohen S, Wills TA. Stress, social support, and the buffering hypothesis. Psychol Bull 1985:98:310-57.

26 Van Veldhoven MJPM, Meijman TF. Het meten van psychosociale arbeidsbelasting met een vragenlijst: de Vragenlijst Beleving en Beoordeling van de Arbeid VBBA. (The Dutch questionnaire on the experience and assessment of work.) Amsterdam: NIA, 1994.

27 Beurskens AJHM, Bültmann U, Kant IJ, et al. Fatigue among working people: validity of a questionnaire measure. Occup Environ Med 2000;57:353-7

28 Van Yperen NW, Snijders TAB. A multilevel analysis of the demands-control model: is stress at work determined by factors at the group level or the individual level? J Occup Health Psychol 2000;5: 182-90. 
29 Sluiter JK, Van der Beek AJ, Frings-Dresen MHW. The influence of work characteristics on the need for recovery and experienced health: a study on coach drivers. Ergonomics 1999;42:573-83.

30 Elders LAM, Burdorf A. Interrelations of risk factors and low back pain in scaffolders. Occup Environ Med 2001:58:597-603.

31 Van der Weide WE, Verbeek JHAM, van Dijk FJH, et al. Relation between indicators for quality of occupational rehabilitation of employees with low-back pain. J Occup Environ Med 1999;56:488-93.

32 Van der Weide WE, Verbeek JHAM, Van den Willering MC. Prognostic factors for chronic disability from acute low-back pain in occupational health care. Scand J Work Environ Health 1999:72:377-92.

33 Van Veldhoven MJPM, Broersen JPJ. Psychische vermoeidheid in de arbeidssituatie. (Psychological fatigue at work.) Gedrag en Organisatie 1999; 12:347-63.

34 Van Veldhoven MJPM. Psychosociale arbeidsbelasting en werkstress. (Psychosocial workload and work stress.) [thesis]. Lisse: University of Groningen, Swets and Zeitlinger, 1996.

35 Weel ANH, Broersen JPJ. Verslag van het SKB-project PAGO-module werkstress. (Report on the SKB-project periodic health survey "occupational stress".) Amsterdam: SKB, 1995.

36 Jackson PR, Wall TD, Martin R, et al. New measures of job control, cognitive demand, and production responsibility. J Appl Psychol 1993;78:753-62.

37 Vercoulen JHMM, Swanink CMA, Fennis JFM, et al. Dimensional assessment of chronic fatigue syndrome. J Psychosom Res 1994; 38:383-92.

38 Vercoulen JHMM, Swanink CM, Fennis JFM, et al. Prognosis in chronic fatigue syndrome: a prospective study on the natural course. J Neurol Neurosurg Psychiatry 1996;60:489-94.

39 Bültmann U, De Vries M, Beurskens AJHM, et al. Measurement of prolonged fatigue in the working population: determination of a cut off point for the checklist individual strength. J Occup Health Psychol 2000;5:411-6.

40 Aiken LS, West SG. Multiple regression: testing and interpreting interactions. Newbury park, CA: Sage, 1991

41 Jaccard J, Turrisi R, Wan CK. Interaction effects in multiple regression. Newburry park: Sage publication, 1990.

42 Demerouti $E$, Bakker $A B$, Nachreiner $F$, et al. A model of burnout and life satisfaction amongst nurses. J Adv Nurs 2000;32:454-64.

43 Frese $M$. Theoretical models of control and health. In: Sauter SL, Hurell JJ, Cooper CL, eds. Job control and worker health. Chichester: Wiley, 1989:107-28

44 Frese M. Social support as a moderator of the relationship between work stressors and psychological dysfunctioning: a longitudinal study with objective measures. J Occup Health Psychol 1999;4:179-92.
45 Kasl SV. An epidemiological perspective on the role of control in health. In: Sauter SL, Hurell JJ, Cooper CL, eds. Job control and worker health. Chichester: Wiley, 1989:161-89.

46 Dwyer DJ, Ganster DC. The effects of job demands and control on employee attendance and satisfaction. Journal of Organizational Behavior 1991;12:595-608.

47 Sauter SL. Moderating effects of job control on health complaints in office work. In: Sauter SL, Hurell JJ, Cooper CL, eds. Job control and worker health. Chichester: Wiley, 1989:91-6.

48 Fox ML, Dwyer DJ, Ganster DC. Effects of stressful job demands and job control on physiological and attitudinal outcomes in a hospital setting. Academic Management Journal 1993;36:289-318.

49 Kushnir T, Melamed S. Work-load, perceived control and psychological distress in Type A/B industrial workers. Journal of Organizational Behavior 1991;12:155-68.

50 Landsbergis PA, Schnall PL, Deitz D, et al. The patterning of psychological attributes and distress by job strain and social support in a sample of working men. J Behav Med 1992:15:379-405.

51 Mullarkey S, Jackson PR, Wall TD, et al. The impact of technology characteristics and job control on worker mental health. Journal of Organizational Behavior 1997; 18:471-89.

52 Orbell S, Gillies B. What's stressful about caring? J Appl Psychol 1993;23:272-90.

53 Parkes KR, Von Rabenau C. Work characteristics and wellbeing among psychiatric health care staff. J Community Appl Soc Psychol 1993;3:243-60

54 Kauppinen-Toropainen K, Kandolin I, Mutanen P. Job satisfaction and work-related exhaustion in male and female work. Journal of Occupational Behavior 1983:4:193-207.

55 Schmidt SH, Meijman TF, Scholten A, et al. Factors contributing to job satisfaction following rehabilitation for musculoskeletal impairments. Journal of Occupational Rehabilitation 1993;3:213-22.

56 Landsbergis PA. Occupational stress among health care workers: a test of the job demands-control model. Journal of Organizational Behavior 1988;9:217-39.

57 Melamed S, Kushnir T, Meir El. Attenuating the impact of job demands: additive and interactive effects of perceived control and social support. Journal of Vocational Behavior 1991;39:40-53.

58 De Jonge J, Janssen PPM, Van Breukelen GJP. Testing the demand-control-support model among health-care professionals: a structural equation model. Work Stress 1996:10:209-24.

59 Warr P. Decision latitude, job demands, and employee well-being. Work Stress 1990;44:285-94.

60 Spector PE, Chen PY, O'Connell BJ. A longitudinal study of relations between job stressors and job strains while controlling for prior negative affectivity and strains. J Appl Psychol 2000;85:211-18. 